\title{
PERSPECTIVES
}

\section{BIG DATA AND DISRUPTIONS IN BUSINESS MODELS}

\section{THE HYPE OF EMERGING TECHNOLOGIES}

There are many challenges to reaping the benefits of the newest, emerging technologies. If it were easy, every business would do it and competitive advantage would easily fade away. It is in fact extremely difficult and challenging for companies to create value with emerging technologies. Every year, Gartner, a respected consultancy company, reviews the newest, emerging technologies and uses its hype cycle concept to explain the path that technologies take. The cycle consists of five phases: (i) the technology trigger phase: the invention of new technology that happens in a research lab, usually at a university (most companies outsource their fundamental research to universities nowadays). (ii) the peak of inflated expectations phase: the technology is discussed by companies at conferences and in the press. There is a great deal of talk about the new technology, but no one has used it yet. R\&D projects are launched. (iii) the disillusionment phase: it turns out that the technology is not as useful as it was thought to be. (iv) the slope of enlightenment phase: here, the valuable fusion of business and technology is explored. (v) the plateau of productivity phase: it is clear how business can use the technology to create value. In Gartner's (2019) emerging technologies hype cycle, technologies such as biorobots, augmented reality cloud, decentralized web, adaptive machine learning, nanoscale $3 \mathrm{D}$ printing, and $5 \mathrm{G}$ are reviewed and positioned in the first phases. Gartner expect that these technologies will reach the plateau of productivity within 5 to 10 years.

Two observations are important and have to be made. First, the newest technologies will generate enormous amounts of data, both at the level of molecules, individual objects and humans; and interconnected devices (things) and humans embedded in complex commercial, logistical, and financial networks. Second, for companies, it would be wise to address these emerging technologies from a 'sensing-data storage-analyzing and responding-learning' perspective. From a business perspective, the sense-store-analyze-respond-and-learn cycle needs to be connected to the hype cycle of emerging technologies. Completing the loop of 'sensing-data storage-analyzing and responding-learning' is a critical success factor for companies. However, as usual, there are complications, in this case there are two. The first is that more data also will imply more noise. It is

ERIC VAN HECK ${ }^{1}$

evanheck@rsm.nl

ORCID: 0000-0002-8058-6640

${ }^{1}$ Erasmus University, Rotterdam School of Management, Rotterdam, Netherlands very challenging to distinguish the signal from the noise, see Silver (2015). The second complication is that data is generated not only inside the firm's applications but also in applications that are run in conjunction with several business partners in so-called business ecosystems; Porter and Heppelmann (2014) would call these business applications a "system of systems." Therefore, the ownership and legality of data becomes a crucial factor that might hamper technologies from reaching the plateau of productivity. 


\section{HOW TO WIN THE DATA RACE?}

Many companies are aware of the potential value of emerging technologies and the digital transformation that they need to make. However, as stated previously, it is not easy to transform companies into digital businesses. The MIT Center for Information Systems Research (CISR) has a long research tradition in analyzing and explaining the so-called critical success factors, a term that was coined in the 1980 s by Jack Rockart, the first CISR research director. Their latest research shows that it is not so much the technology, but more the organizational capabilities, that drive success. In their book Leading Digital: Turning Technology into Business Transformation, Westerman, Bonnet, and McAfee (2014) analyze the performance of 400 companies around the world. They distinguish four clusters (beginners, fashionistas, conservatives, and digital masters) that are distinguished by the capabilities that they incorporate. Digital leadership is about the development of capabilities that will enable the design and implementation of useful business applications (WHAT) and those that will enable transformation (HOW). The first group, digital capabilities, enables the creation of a compelling customer experience, exploiting the power of core operations, and reinventing business models. The second group, leadership capabilities, deals with crafting a digital vision, engaging the organization at scale, governing the transformation, and building technology leadership capabilities. Both digital and leadership capabilities are necessary conditions for attaining higher firm performance levels. Companies that incorporate these capabilities perform exceptionally better, both in terms of revenue generation, profitability, and market valuation. Digital transformation programs are crucial for the survival of companies. Take, for example, Royal Philips, an established, century-old conglomerate with dwindling results. With a new CEO in 2011, it established a digital transformation program, called Accelerate, that created a new foundation for a digitally enabled company that moved from product to software service orientation, see Mocker, Ross, and van Heck (2014). A crucial component of the transformation was to eliminate unrewarded process complexity and simplify processes, roles, and systems around the world. By contrast, the transformation stimulated rewarding product complexity such as integrated health solutions with advanced scanning, decision analysis, and artificial intelligence components. Recently, Peter Weill and Stefanie Woerner (2018) published the latest CISR research in their book What's Your Digital Business Model? Six Questions to Help You Build the Next-Generation Enterprise. They emphasize that digital transformation is not about technology but rather about change. They distinguish four business models based on business design dimensions (value chain versus ecosystem) and end customer knowledge (partial versus complete), namely: supplier, omnichannel, modular producer, and ecosystem driver. Ecosystem drivers outperform all other business models.

\section{WHAT IS THE BUSINESS VALUE AND FOR WHOM?}

There are three fundamental ways for companies to create business value:

- To create business that is more efficient-resources are used in a better way

- To create business that is more effective-end customers are served in a better way

- To create new business-new business models create sustainable value.

In all three of these value creation strategies, the use of Big Data and advanced analytics play a crucial role. First, take, for example, the retailer's efficiency of the last mile delivery of packages that customers purchase online. Albert Heijn, a large retailer in Europe, felt a need to redesign its last mile delivery process. It came up with an intelligent approach that combined the data of the incoming online calls for delivery, with the pricing of time slots for delivery, and the efficient bundling of deliveries in trucks that served the same area (Agatz, Campbell, Fleischmann, \& Savelsbergh, 2011). The result was a higher utilization of truck capacity and a lower number of truck kilometers reducing the carbon footprint of last mile deliveries in cities.

Second, Royal FloraHolland, the world leading market grower of flowers and plants, is transforming to become an ecosystem driver that is more effective in the floriculture world. One way is to redesign the flower auction markets and augment the auctioneers with advanced analytics capabilities. Its customers, in this case professional wholesalers and retailers, will get the right products for the right price at the right time. Because of the perishability of flowers, time is a crucial source of value. Based on the analysis of millions of transactions, they created an advanced decision support system that enable auctioneers to make better decisions and balance revenue with turnaround time (Lu, Gupta, Ketter, \& van Heck, 2019).

Third, the most challenging strategy is to create new business. Car2Go, an internationally operating car rental and sharing company, rents out cars to customers. In cities such as 
New York, Amsterdam, and Stuttgart, one can pick up a car from the street and leave it anywhere. A pilot with electric cars in San Diego, Amsterdam, and Stuttgart showed the potential of a new business model for electric cars. With the help of advanced algorithms and different data sets, such as weather, short-term local electricity prices, and car rental demand, the fleet of electric cars can simulate a virtual power plant (Kahlen, Ketter, \& van Dalen, 2018). The combined batteries of these electric cars can store electricity generated by the sun and wind, the renewable energy providers. On overcast and/or still days, electricity stored in the electric car batteries can be sold via the smart grid to the general public. Therefore, Car2Go might shift its business model from a "car rental" to a "car rental and electricity storage and sales" company.

\section{WHAT ARE THE TRANSFORMATIONAL CHALLENGES?}

Digital transformation has many challenges and nowadays most companies face these challenges. The first is that most companies do not have a common digitized platform. They have a plethora of applications and systems that were built with relatively outdated technology and software, such as Enterprise Resource Planning applications. The transformation to real time access to enormous data sets with advanced human and machine learning capabilities will take some time and effort.

The second challenge is how employees are able to work with the new advanced machine intelligence capabilities. Are employees engaged in the transformation or do they feel threatened that robots will take over their jobs? In most organizations, users of technology cannot or will not engage in the transformation.

The third challenge is the lack of digital leadership by the board of the company. Most board members are not digital savvy and therefore it is difficult for them to create a vision and mission for the company that is sustainable in a digitizing world. The board's lack of commitment to transformation is usually a sign to the rest of the company to slow down the pace of change. The fourth challenge relates to data ethics, privacy, and algorithm accountability. Companies acquire detailed data about their customer preferences. Digital technology moguls, such as Alibaba, Amazon, Apple, Facebook, Google, Microsoft, Samsung, and
Tencent gather very detailed data about every aspect of their customer's life cycle. Combined with advanced machine learning tools, these databases create data power and stimulate an important discussion about the rules and responsibilities of companies. Who is responsible when companies create algorithms that discriminate against employees or customers? Who owns the data that is generated by customers? In May 2018, the European Union implemented a new regulation called the General Data Protection Regulation, that provides data protection and privacy for all citizens of the European Union and the European Economic Area, including the transfer of personal data outside the European space. In other areas around the world, most citizens are not protected at all.

\section{REFERENCES}

Agatz, N., Campbell, A., Fleischmann, M., \& Savelsbergh, M. (2011). Time slot management in attended home delivery. Transportation Science, 45(3), 435-449. doi:10.1287/trsc.1100.0346

Gartner. (2019). Hype cycle of emerging technologies 2019. Retrieved from https://www.gartner.com/en/documents/3956015/hypecycle-for-emerging-technologies-2019

Kahlen, M. T., Ketter, W., \& van Dalen, J. (2018). Electric vehicle virtual power plant dilemma: Grid balancing versus customer mobility. Production and Operations Management, 27(11), 2054-2070. doi:10.1111/poms.12876

Lu, Y., Gupta, A., Ketter, W., \& van Heck, E. (2019). Dynamic decision making in sequential business-to-business auctions: A structural econometric approach. Management Science, 65(8), 3853-3876. doi:10.1287/mnsc.2018.3118

Mocker, M., Ross, J. W., \& van Heck, E. (2014). Transforming Royal Philips: Seeking Local Relevance While Leveraging Global Scale. In MIT Sloan CISR Working Paper No. 394, February 2014. Cambridge, USA: MIT Sloan Centre for Information Systems of Research (CISR).

Porter, M. E., \& Heppelmann, J. E. (2014). How smart, connected products are transforming competition. Harvard Business Review. Retrieved from https://hbr.org/2014/11/how-smart-connected-products-are-transforming-competition

Silver, N. (2015). The signal and the noise: Why so many predictions fail, but some don't. New York, NY: Penguin Books.

Weill, P., \& Woerner, S. (2018). What's your digital business model? Six Questions to help you build the next-generation enterprise. Cambridge, UK: Harvard Business Review Press.

Westerman, G. Bonnet, D., \& McAfee, A. (2014). Leading digital: Turning technology into business transformation. Cambridge, UK: Harvard Business Review Press. 